\title{
University performace through Multiple Factor Analysis
}

\author{
Delimiro Visbal-Cadavid ${ }^{1}$, Mónica Martínez-Gómez ${ }^{2}$, Rolando Escorcia-Caballero ${ }^{3}$ \\ ${ }^{1}$ Department of Industrial Engineering, University of Magdalena, Colombia, ${ }^{2}$ Department \\ of Applied Statistics, Operatios Research and Quality, Polytechnic University of Valencia, \\ Spain, ${ }^{3}$ Faculty of Education, University of Magdalena, Colombia.
}

\begin{abstract}
This work applies the Multiple Factor Analysis (MFA) as an exploratory methodology to analize the indicators of the education's management that belong to 32 Colombian public Higher Education Institutions (HEIs) along the year 2013.

The product of this work indicates that the majority of HEIs have similar structures, being different and better scored the following: La Universidad Nacional (UNAL), Antioquia (UDEA), Nacional Abierta y a Distancia (UNAD), Pamplona y del Valle. Also the UDEA has a high development in extension, formation, capacity and research which is considered one of the best HEIS in the country. The university of Valle has a high degree of welfare, formation and extension, besides moderate capacities on research in comparission with the UDEA wich is superior to the rest of the HEIs. Pamplona has too a high level of formation, extension and moderate weflare, research and capacity in relation to the UNAD. It worth to mention that UNAL is the best located on extension. However, it is surpassed by other University (UDEA) because has a better development in some variables associated to research and extension. To finish, there are other HEIs with too many weaknesses on the indicators of the education's management wich are UFPS Ocaña, Sucre and Pacifico. These universities show certain problems of research, extension and capacity, but fundamentally strong shortcomings in formation and welfare.
\end{abstract}

Keywords: Multiple Factor Analysis; Education's key performance indicator; Higher Education Institutions. 


\section{Introduction}

There are some challenges inside in the higher education institutions (HEIs), the actions and strategies that they must face to mobilize the resources and sources of financing are exhaustive but necessary for reach goals, It must go through for the determination and priorities of certains variables in each HEI, in order to achieve a sustainable financing that allows the expansion and diversification of the education system as also improve the quality in higher institutions.

In this order of ideas, the development of HEIs is undoubtedly amazing and leading a good place among the challenges of higher education in Colombia. The public policy of the actual government is focused on considering education as the fundamental axis of economic and social development, which implies the need to adequately allocate resources in a way that guarantees compliance with the mission and substantive functions of HEIs. That is, Teaching, Research and Extension.

As a result of the agreements between the Ministry of National Education from Colombia (MEN) and the "Sistema Universitario Estatal" (SUE), since 2003 a series of indicators education's management are defined and make bases for the distribution of resources model, which constitute an one capacity index and four results index from SUE. These five groups, as they will be referred to below, are made up of a series of variables associated with each dimension.

As in this case, in many research contexts it is common to find situations when an observation group is described in terms of several categories of variables. This structure can be hidden when a global analysis of the information is made. So, the Factor Analysis consider different groups of variables in a single analysis, that mean, without considering the existence of variables of a different nature. However, a more ambitious analysis must take, treat and analyze the information in terms of multiple tables, not limited to the search of relationships between variables or the characterization of individuals, in contrast to it should be extended to a comparative analysis that consider the present realities within in each tables and the relationship between tables of different nature.

The reach of this work is to study by the Multiple Factor Analysis (MFA), multiple table analysis technique, the conduct of the HEIs according to their development along the year 2013 in each variable groups and the relationships between these groups (categories or dimensions) and the relations with HEIs.

This technique was developed by the Professors Brigitte Escofier and Jérôme Pagès at the French School of Data Analysis (Escofier \& Pagès, 1992). Wich that since its inception has established itself with great versatility with the treatment of information of three dimensions. 
There are many research it can be refer to, such as the study realized by Næs, Berget, Hovde, Ares, Varela (2017); Tomic, Berget, \& Næs (2015); Vitelleschi and Chavasa. (2015), manifesting its potential in the theoretical and empirical field and many areas. These works reveal how the (MFA) is a multiple table analysis technique with a whole philosophy of comparative analysis too, both graphically and through numerical indicators, of different data sets.

\section{Sample}

The information used in the present work corresponds to the 29 indicators of the education's management from 32 Colombian public universities belonging to SUE, for the year 2013. These indicators reflect the different dimensions of development of HEIs, that is, Capacity, Education, Research, Welfare and Extension, participating as active variables in the present study.

The study is carried out on the standardized variables so that the variables, which are measured in different units, can be comparable.

A multivariate outliers analysis was carried out using the Mahalanobis distance, the results indicate the non-existence of outliers.

Table 1 shows the 32 Colombian public universities (HEIs) considered in the study. 
Table 1. Universities in study

\begin{tabular}{|c|c|}
\hline HEIS & HEIS \\
\hline Univ. Nacional de Colombia (UNAL) & Univ. del Atlántico \\
\hline Univ. Pedagógica Nacional & Univ. del Valle \\
\hline $\begin{array}{l}\text { Univ. Pedagógica y Tecnológica de Colombia } \\
\text { (UPTC) }\end{array}$ & Univ. Industrial de Santander (UIS) \\
\hline Univ. del Cauca & Univ. de Cartagena \\
\hline Univ. Tecnológica de Pereira & Univ. de Nariño \\
\hline Univ. de Caldas & Univ. del Tolima \\
\hline Univ. de Córdoba & Univ. del Quindío \\
\hline Univ. Surcolombiana & $\begin{array}{l}\text { Univ. Francisco de Paula Santander (UFPS)- } \\
\text { Cúcuta }\end{array}$ \\
\hline Univ. de La Amazonía & $\begin{array}{l}\text { Univ. Francisco de Paula Santander (UFPS)- } \\
\text { Ocaña }\end{array}$ \\
\hline Univ. Militar Nueva Granada & Univ. de Pamplona \\
\hline Univ. Tecnológica del Chocó & Univ. del Magdalena \\
\hline Univ. de Los Llanos & Univ. de Cundinamarca \\
\hline Univ. Popular del Cesar & Univ. de Sucre \\
\hline Colegio Mayor de Cundinamarca & Univ. de La Guajira \\
\hline Univ. del Pacífico & Univ. Distrital \\
\hline Univ. de Antioquia (UDEA) & Univ. Nacional Abierta y a Distancia (UNAD) \\
\hline
\end{tabular}

Instead, the table 2 shows the 29 indicators of the education's management associated with each of the 5 categories. 
Table 2. Study variables and their codification

\begin{tabular}{|c|c|}
\hline Group & Variable/Codification \\
\hline \multirow{4}{*}{ 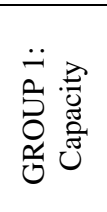 } & Teachers equivalent full time / DTCE \\
\hline & Administrative staff expenses / GPA \\
\hline & Financial resources / RECFIN (COP) \\
\hline & Square meters / $\mathrm{Mt}^{2}$ \\
\hline \multirow{12}{*}{ 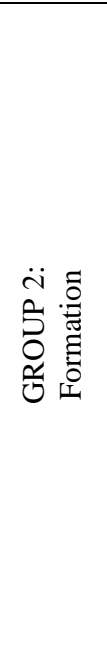 } & Number of undergraduate programs / NPROGPRE \\
\hline & Number of Postgraduate Programs / NPROGPOST \\
\hline & First year enrollment / MATPRIMER \\
\hline & Undergraduate enrollment / MATPRE \\
\hline & Postgraduate enrollment / MATPOS \\
\hline & Undergraduate graduates / GRADPRE \\
\hline & Postgraduate graduates / GRAPOST \\
\hline & Saber Pro Tests in English / SABING \\
\hline & Saber Pro Tests / SABPRO \\
\hline & Employability / EMPLE \\
\hline & Colombian students mobility abroad / MOVESTCOL \\
\hline & Foreign students in mobility in Colombia / MOVESTEXT \\
\hline \multirow{5}{*}{ 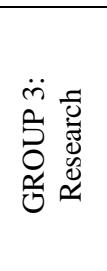 } & Research groups recognized by Colciencias / GRUPOS \\
\hline & Indexed journals / REVISTAS \\
\hline & Articles published in indexed journals / ARTICULOS \\
\hline & Patents / PATENTES \\
\hline & Teacher mobility / MOVDOC \\
\hline \multirow{3}{*}{ 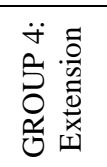 } & Students in extension activities / ESTEXT \\
\hline & Contracts with organizations / VINENT \\
\hline & Licensed products / PROLIC \\
\hline \multirow{5}{*}{ 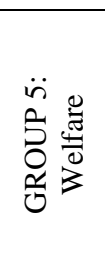 } & Socioeconomic support in undergraduate / APSEPRE \\
\hline & Socioeconomic support in postgraduate / APSEPOS \\
\hline & Students Withheld/ RETENIDOS \\
\hline & Health programs / PROSAL \\
\hline & Student approval rate / TAPRO \\
\hline
\end{tabular}

Fuente: Ministry of National Education from Colombia. COP: Colombian Pesos 


\section{Results}

\subsection{Bartlett's Test of Sphericity}

The Chi-Square value of the Bartlett's Test of Sphericity is with 1,796.935 with 406 degrees of freedom and $p-$ value $<2.11 \times 10^{-16}$, indicating that the data matrix is adequate for a Factor Analysis.

\subsection{Weighting of groups of variables}

Next in table 3 we show the results of the Principal Components Analysis (PCA) for each group for the year 2013, in order to determine the weights of variables of each group.

This table indicates, for example: The first own value of the PCA of each Capacity group is 3,374 , therefore the weight for each variable of capacity group is the inverse, $1 / 3,374=$ 0.296 . The PCA of group indicates that $94.4 \%$ of the variability of variables group is explained with two factors.

Table 3. Results of the Principal Components Analysis (PCA) for each group

\begin{tabular}{cccc}
\hline Group & $\begin{array}{c}\text { PCA First own } \\
\text { value group }\end{array}$ & $\begin{array}{c}\text { Weighting of group of } \\
\text { variables }\end{array}$ & $\begin{array}{c}\text { Variance percentage } \\
\text { explained with two } \\
\text { factors }\end{array}$ \\
\hline Capacity & 3.374 & 0.296 & 94.40 \\
Formation & 8.267 & 0.121 & 82.03 \\
Research & 4.458 & 0.224 & 97.51 \\
Extension & 2.107 & 0.475 & 94.06 \\
Welfare & 3.688 & 0.271 & 84.50 \\
\hline
\end{tabular}

Source: Own analisys

\subsection{Multiple Factor Analysis (MFA)}

To apply the global analysis (MFA) for the year 2013, we found that 2 factors determinate $79.55 \%$ of the variability contained in the 29 analyzed variables. Table 4 shows the own values and the variability explained by each of the 2 components. 
Table 4. Values of the global AFM

\begin{tabular}{ccc}
\hline & F1 & F2 \\
\hline Own Value & 4,548 & 0,654 \\
Variability (\%) & 69,556 & 9,995 \\
\% accumulated & 69,556 & 79,551 \\
\hline \multicolumn{2}{c}{ Source: Own analisys }
\end{tabular}

Source: Own analisys

The correlations between the variable and the factor correspond to the ranges of figure 1 . The existence of common factors in groups is justified by their correlation. The high correlation of factor 1 is interpreted as a common axis to the five groups, while factor 2 significantly reduces its relation for these groups, being "Extension" the hightest category with this second factor. This table shows too how the factor $1(\mathrm{~F} 1)$ is more associated to the variables "Capacity" group followed by "Formation" group "Research" and "Welfare" group.

Figure 1 shows the distribution of factors, which are formed in the first axis by Welfare, Formation, Capacity and Research, while near the second axis there is the Extension group.

Regarding the contribution percentage of each variables group to the factors, we found that $21.3 \%$ of the inertia collected by the first factor is caused by the variables capacity group; while $21.07 \%, 20 \%$ and $18.6 \%$ is caused by the variables of formation, research and welfare, respectively. On the other hand, this factor explains with $99.1 \%$ the dispersion of the different HEISs according to their conduct with the variables capacity group. The absolute contribution is "Extension" wich second factor is $38.5 \%$. The squared cosines indicate the quality of the representation, indicating the quality of the first factor and the variability present in the four groups, not the same for the second factor.

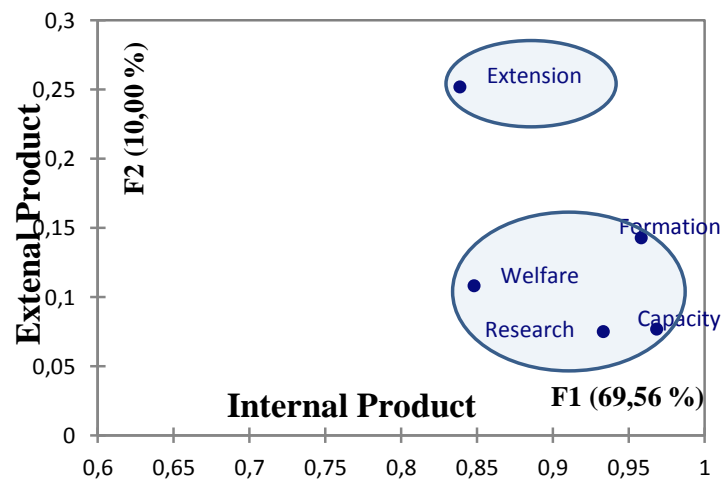

Figura 1: Distribution of Factors. Source: Own analisys. 
The $\mathrm{Lg}$ coefficients indicate that the Extension group $(\mathrm{Lg}=1,12)$ contains the most heterogeneous variables in relation to the rest of the groups and the most homogeneous are Research $(\operatorname{Lg}=1,01)$ and Capacity $(\operatorname{Lg}=1,01)$, followed by Welfare $(\operatorname{Lg}=1.04)$ and formation $(\mathrm{Lg}=1.05)$.

The RV coefficients are defined as a measure of association between the groups. These coefficients show a strong similarity in the existing structure between the Capacity group with the Formation and Research groups, and between the Formation - Research group and Welfare, that's mean, there is a high correlation in the groups. Also the Capacity group has the most correlation with the rest, followed by Formation, as indicated by the MFA.

Figure 2 shows the variables representation to its correlation with the factor axes. The arrows indicate the directions of growth of variables in the factorial space, which allows to identify graphically the variables with greater weight in each component. The center of the circle represents of correlations the average of all the variables.

The different variables are mainly correlated depending on the proximity of their vectors, for example, if the angles of these variables approach to zero, they will be more correlated and vice versa. Now, the variable PROLIC forms an angle of 90 degrees with the GPA and with MOVESTEXT, which indicates non association between the firsts with the other two. Regarding the variables group of the Research dimension, we see the highly correlated with each other, except MOVDOC.

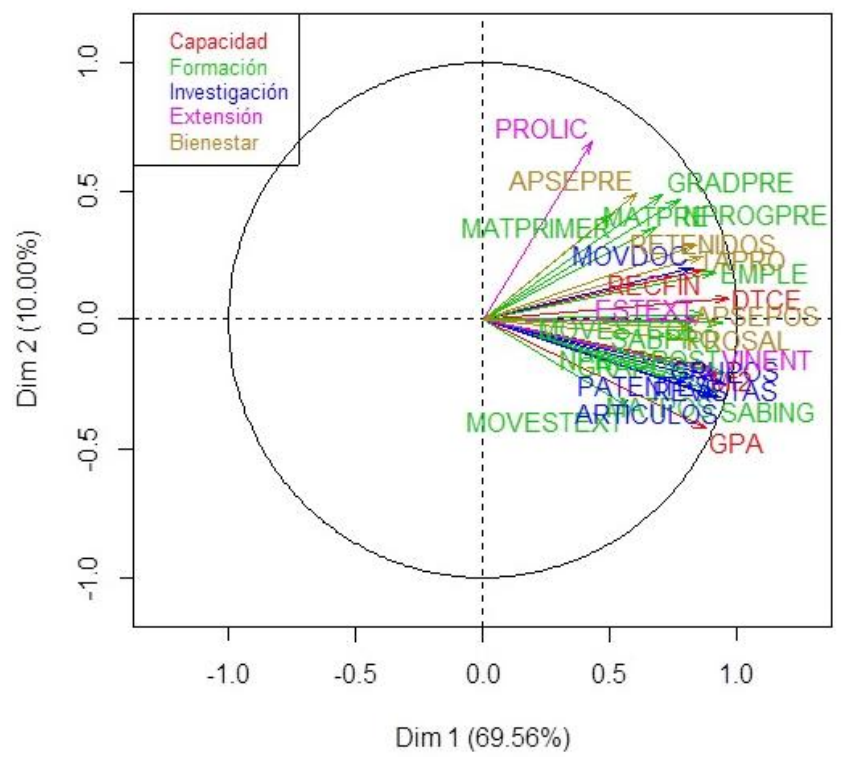

Figure 2: Representation of the variables. Source: personal compilation 
The MFA allows to project in a factorial plane $(1,2)$ the 32 HEIs and describe their conduct according to their ranges (figure 3). For this, we understand the greater development of HEIs, their formation, capacity, research and welfare, as they move to the right of the plane, more development in their licensed products, links with entities and students in extension activities. In this way, two HEIs can have the same behavior with respect to an axis (internal product) such as Pamplona and Militar and the factor comprised by formation, capacity, research and welfare, however, have a different behavior with the second axis "product external".

The UNAL has the best development in capacity, research, welflare, but low standing in Extension, while the UDEA growth in the plane, being the second HEIs with the best development in capacity, research, welfare but first in extension. Besides, the universities of the Pacific, Colegio Mayor de Cundinamarca, Amazonia, Sucre, UFPS Ocaña and Nariño present similar characteristics and at the same time a low standing. So in general terms we can interpret figure 3 depending if similar HEIs be close to each other.

Figure 3 also allows us to visualize the structure and similarity of the HEIs under analysis. As can be seen, the majority of this institutions have the same structure, with some differences like a (UNAL, UDEA, UNAD, Pamplona and Valle). Now, the strengths / weaknesses of each IES can be analyzed, as in the case of the UDEA, which has a high degree of development in extension, formation, capacity and research, considered one of the best among HEIs. The graph shows too some vectors of capacity and research that are not as strong as extension and welfare. In the case of the Valley, the degree of welfare, formation, extension, capacity and research are high in relationship with the UDEA but superior to the rest of the HEIs. Pamplona has a high level of formation and extension, but moderate welfare, research and capacity in relation to UNAD.

With respect to UNAL, we can indicate it how the best located in the axis 1 (internal product), however when it compared with the rest of the HEIs, it is surpassed by the UDEA due to its better performance in the variables of the extension groups and welfare. 


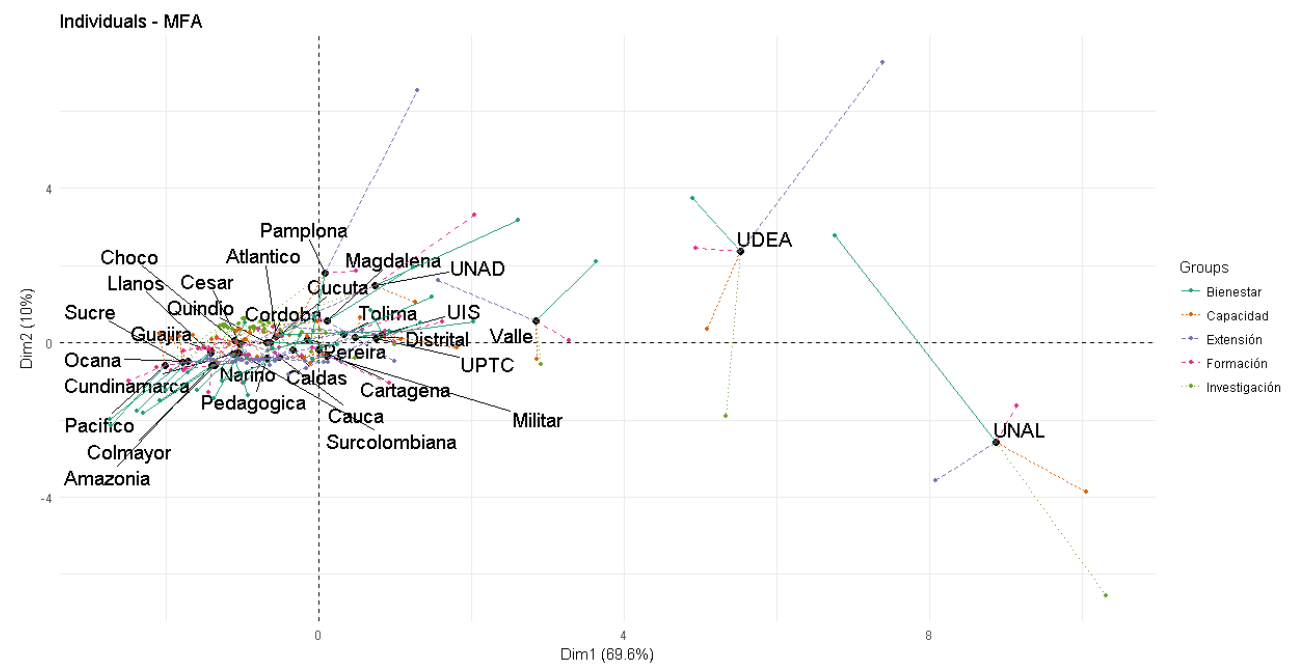

Figure 3: Representation of HEIs with their categories. Source: Personal compilation.

The HEIs that exhibit the most weaknesses (third quadrant) are the Universities of the Pacific, Colegio Mayor de Cundinamarca, Amazonia, Sucre, UFPS Ocaña, Chocó and Nariño. Of these, the Universidad del Pacifico is the one with the lowest development. These HEIs must greatly improve the variables of the formation, especially the universities of the Pacific and Colegio Mayor de Cundinamarca. For its part, the University of Chocó is the one that presents a better standing in the Welfare and Extension groups. Regarding the variables of the Research group, all these universities have a similar profile (quite poor), a similar situation is presented with the Capacity group. The University of Nariño lead in some variables such as Capacity and Research group. In general terms, all these HEIs must make a great effort to greatly improve all management indicators.

\section{References}

Escofier, B. y Pagès, J. (1992). Análisis factoriales simples y múltiples objetivos, métodos e interpretación. Servicio Editorial de la Universidad del País Vasco. Bilbao. España.

Næs, T., Berget, I., Hovde, K., Ares, G. y Varela P. (2017). Estimating and interpreting more than two consensus components in projective mapping: INDSCAL vs. multiple factor analysis (MFA). Food Quality and Preference. 58. 45-60.

Tomic, O., Berget, I. y Næs, T. (2015). Comparison of generalised procrustes analysis and multiple factor analysis for projective mapping data. Food Quality and Preference, 43, 34-46.

Vitelleschi, M.S. y Chavasa, V. (2015). Análisis factorial múltiple para la caracterización de variedades de trigo pan en diferentes ambientes. Revista FABICIB, 19. 113-120. 